\title{
A Review on Recent Progression of Modifications on Titania Morphology and its Photocatalytic Performance
}

\author{
Nor Amira Marfur, ${ }^{1}$ Nur Farhana Jaafar, ${ }^{1, \star}$ Melati Khairuddean ${ }^{1}$ \\ and Norazzizi Nordin ${ }^{1}$ \\ ${ }^{1}$ School of Chemical Sciences, Universiti Sains Malaysia, 11800 USM Penang, Malaysia \\ * Corresponding author: E-mail: nurfarhana@usm.my \\ Tel: 604-6533566 Fax: 604-6574854
}

Received: 04-02-2019

\begin{abstract}
Titanium dioxide $\left(\mathrm{TiO}_{2}\right)$ has been broadly used as a photocatalyst because it has good stability and performance for degradation of pollutants. On the other hand, its efficiency as photocatalyst is limited since it can only be excited under UVlight radiation and has a rapid electron-hole recombination that occurs during the photodegradation. There are many studies focusing on adjusting the synthesis methods, addition of dopants and modifying the $\mathrm{TiO}_{2}$ structure to enhance its photocatalytic performance. Among them, synthesis of $\mathrm{TiO}_{2}$ as porous nanoparticles as one of the strategies in modifying the $\mathrm{TiO}_{2}$ structure has gained attention due to its benefits for better adsorption and accessibility of various pollutants onto the reactive site of catalyst, thus enhancing the photocatalytic performance. In this review, we recapitulated on modifications of synthesis methods for $\mathrm{TiO}_{2}$ and their effect on the structure along with the photocatalytic performance. Recent progress for $\mathrm{TiO}_{2}$ in terms of synthesis approaches, effect of dopants, modified structures, and applications are also briefly discussed in this review.
\end{abstract}

Keywords: Morphology; titania nanoparticles; porosity; photocatalytic activity.

\section{Introduction}

Titanium dioxide is classified as a transition metal oxide which exists in anatase, rutile, or brookite crystalline structures. ${ }^{1-3}$ Many studies have been done by researchers regarding $\mathrm{TiO}_{2}$ because it is inexpensive, chemically and thermally stable, eco-friendly, and widely used for different applications such as for the production of dye-sensitised solar cells, sunscreen, and water purification. ${ }^{4-6} \mathrm{Be}-$ sides functioning as a catalyst, $\mathrm{TiO}_{2}$ also acts as an additive, promoter, and transporter during the catalytic reaction. ${ }^{7-10}$ The extensive usage of $\mathrm{TiO}_{2}$ in photocatalytic degradation is due to its capability in mineralisation of organic pollutants such as dye and chlorophenol to less harmful compounds as shown in Fig. $1 .{ }^{11-14}$ However, its efficiency as a photocatalyst is limited since it can only be excited under UV-light due to a wide band gap which is around $3.2 \mathrm{eV}$ and high electron-hole recombination rate during photodegradation. ${ }^{15-17}$

The effectiveness of $\mathrm{TiO}_{2}$ as a photocatalyst can be enhanced by increasing the surface area and its crystallin-

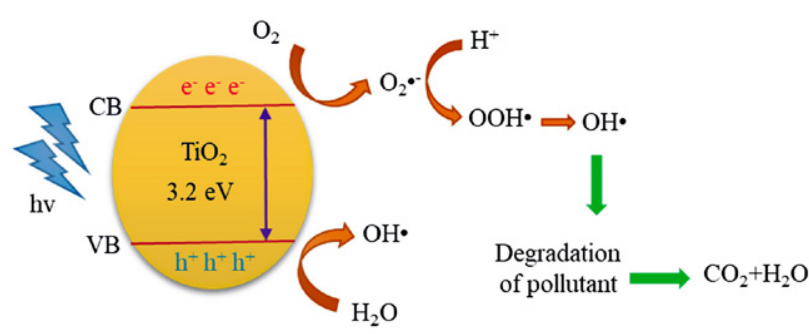

Fig. 1. The schematic diagram of mechanism for photocatalytic degradation using titania.

ity, while decreasing the particle size will strongly contribute in reducing the band gap. The band gap energy also can be reduced by pairing with other semiconductors. Apart from that, the generation of abundance site defects such as $\mathrm{Ti}^{3+}$ site defects (TSD) and oxygen vacancies (OV) can help function as electron acceptors which inhibit the electron-hole recombination and assist the charge carrier migration. ${ }^{18}$ Therefore, there are various modifications on $\mathrm{TiO}_{2}$ forms such as nanotubes and thin films. ${ }^{19-21}$ Recent- 
ly, porous transition metal oxide has also been studied widely since it improves its original properties. This favourable modification gives many benefits for various applications since it can result in varied forms including nanoparticles, fibres, and films besides possessing a consistent large pore pattern which increases surface area, gives an ordered structure and adjustable pore diameter. ${ }^{22}$ Mesoporous titania has been intensely studied compared to others due to its diverse applications as a photocatalyst and supercapacitor. ${ }^{23-26}$ The first mesoporous $\mathrm{TiO}_{2}$ was synthesised via a sol-gel approach which yielded hexagonal pores that are particularly organised. ${ }^{27,28}$ Afterwards, many methods have been introduced and modified according to the Evaporation-Induced Self-Assembly (EISA) approach using varied titanium precursors or template surfactants to synthesise different morphologies of $\mathrm{TiO}_{2}$ for specific applications. ${ }^{29-32}$

According to previous studies, organic surfactant is greatly contributing in controlling the size and shape of precursor during the synthesis. It also acts as a soft template and dispersant to form various scales of porous structures such as microporous, mesoporous and microporous with high crystallinity. ${ }^{33-36}$ There are several types of surfactants which are anionic, cationic, nonionic, and polymeric fugitive materials used to construct different morphologies of materials while greatly enhancing the surface area, pore volume, and other related properties. ${ }^{37-44}$ Organic surfactant acts as a template or SDA (surface directing agent) in preparing porous materials to create the interior part of the building blocks which are pores. The co-existence of chemically bonded hydrophilic (polar) part as well as a hydrophobic (non-polar) hydrocarbon in a molecule of surfactants makes them suitable to be used as SDA. For instance, the presence of cetyl-trimethylammonium bromide (CTAB) which is a cationic surfactant will create a micellar system that contributes as the template to form the interaction with a precursor when the degree of hydration increases. These molecules assemble in the solvent to form micelle and have a high molecular weight. This situation is a primary reaction in preparing highly porous and uniform materials..$^{45,46}$

Therefore, this review will be critically discussing the recent progress for $\mathrm{TiO}_{2}$ in terms of modification of titania morphology using different surfactants, synthesis methods, the role of dopants and their photocatalytic performance to help other researchers to further the study in this field.

\section{Type of Surfactants}

Surfactants can be categorised into different groups based on the ions charged at the hydrophilic part. They act as a template to form pores on the metal oxide where the pore size can be controlled by their alkyl chain lengths. For instance, cetyl-trimethylammonium bromide (CTAB) with a longer alkyl chain produces bigger pores compared to $n$-dodecyl-trimethylammonium bromide (DTAB) which has a shorter alkyl chain. The pore morphology of the metal oxide can also be modified by varying the ratio of the reaction mixture and synthesis conditions such as the basic $\mathrm{pH}$ of the solution which can produce smaller pores. When the critical micellar concentration of the surfactant is achieved, micelles form and the dispersion effect occurs which produces a more porous material. Besides that, ionic and non-ionic surfactants use different mechanisms to assemble micelles as a template for pore formation. Ionic surfactant has an amphiphilic nature in which micelles can be assembled by electrostatic interactions while non-ionic surfactant involves hydrogen bonding in the formation of metal oxide-surfactant composites for the material framework organisation. However, the strong reactivity between ionic surfactant and material walls makes it difficult to be removed during calcination and may collapse the material structure. Therefore, for certain synthesis conditions, non-ionic surfactant is preferable since it is easier to be removed and only needs much lower temperature during calcination. ${ }^{47,48}$ Fig. 2 shows a general micellisation of surfactants that occurs during the synthesis of an intended material.

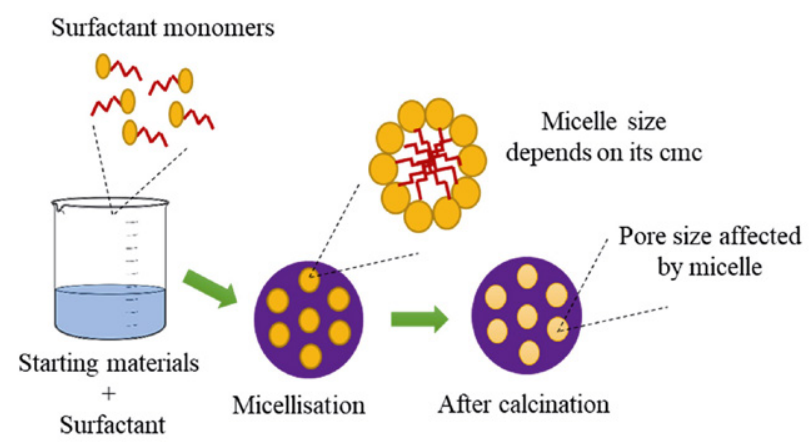

Fig. 2. The general illustration of micellisation of surfactants during synthesis.

\section{1. Anionic and Cationic Surfactants}

Generally, anionic and cationic surfactants are classified as detergents or soaps composed of hydrophilic at the end of the chain which either contains cation or anion. Surfactants have remarkable characteristics that allow them to greatly contribute for the generation of intended materials, namely the production of hollow parts by their aggregation behaviour after being calcined. Besides, they can give a significant effect to the extension and particle properties. ${ }^{49}$ In addition, the alteration on the concentration plays a significant role during the synthesis. Micelles will start to form when the concentration increases up to a critical micelle concentration $(\mathrm{cmc})$. However, the precipitation will only occur if the concentration of surfactant surpasses the product solubility which can reduce the interaction of the surfactants with other compounds. ${ }^{38-41,50}$ 
Mohamed et al. had used sodium dodecyl sulphate (SDS) which is an anionic surfactant as a pore forming agent to synthesise a series of $\mathrm{TiO}_{2}$ nanoparticles using the hydrothermal approach. The usage of SDS was to synthesise titania yielding a high surface area; mesoporous as well as the nanoparticle crystals of anatase $\mathrm{TiO}_{2}$. Besides that, the $\mathrm{pH}$ of the starting material mixture also affected the production of the anatase-rutile phase while preparing these photocatalysts. ${ }^{40}$ The framework alteration for inorganic/organic compounds would occur in order to stabilise interlinkage energy by manipulating the morphology of titanium polymer which then modified the local density and interface charge aspects..$^{39,42}$

Casino et al. had synthesised mesoporous $\mathrm{TiO}_{2}$ nanocrystalline via a facile sol-gel method using an inexpensive titanium oxysulphate starting material with several cationic surfactants which were cetyl-trimethylammonium bromide (CTAB), cetyl-trimethyl-ammonium chloride (CTAC), benzalkonium chloride (BC) and octadecyl-trimethyl-ammonium bromide $\left(\mathrm{C}_{18} \mathrm{TAB}\right)$. Different templates as well as calcination temperatures while producing mesoporous titania nanocrystalline resulted in different features such as chain lengths, counter ions, and morphologies. ${ }^{51}$ Addition of surfactant in the starting material mixture produced crystal structures with the anatase phase and smaller grain sizes which agglomerated after a prolonged heat treatment. Generally, bromide counter ions were less hydrated than chloride, thus the micelles formed had more effectual neutralisation charge at their surfaces, considering the effectiveness of micellisation could be affected by the counter ion condensation. Substantial bromide counter ion could also hinder state alteration from anatase to rutile while further stabilising that phase during titania precipitation. In addition, there was the hydrolysis of titanium oxysulphate along with an intermediate compound production firmly attached at the surfactant's hydrophilic group. Therefore, the characteristics of alkyl chain affected the micelles surface charge densities to promote the hydrolysis process. The decrease in micellisation usually could be related to an increment of alkyl chain on the polar group prompted by the molecule hydrophobic feature. Besides that, CTAB greatly contributed in maintaining the anatase and small-scale crystal framework, though after protracted heating that homogenised grains. ${ }^{52,53}$ Samples BC-450 and BC-650 exhibited lower degrees of porosity by having low surface area compared to CTAB samples. Calcination step is known for template withdrawal to improve the degree of crystallisation besides influencing the arrangement of mesoporous titania structure. ${ }^{54}$

Li et al. had prepared monodisperse and homogenous mesoporous titania spheres in nano-scale via the solgel approach using CTAB as a soft template or pore-forming agent and doped with nitrogen through the hydrothermal approach. Nitrogen doped mesoporous $\mathrm{TiO}_{2}$ spheres produced had showed significant properties like large surface area, proportionately tiny particles in the anatase phase, along with splendid UV-Vis absorption. Thus, the characteristics could greatly contribute in enhancing the photoactivity of Rhodamine B under visible light. ${ }^{55}$

Jaafar et al. had successfully synthesised mesoporous titania nanoparticles (MTN) via the microwave-assisted method with CTAB as a surfactant for the photodegradation of 2-chlorophenol under visible light. These materials possessed smaller particle sizes, smoother pore structure, as well as more TSD and OV distribution. Increase in microwave power density had highly hydrated the surfactant chains and resulted in better interlinkage with solutions containing titanium ions. ${ }^{18}$ In 2017, they had further doped silver into MTN (Ag-MTN) by applying the same method and surfactant which resulted in better photocatalytic performance with lower band gap compared to their previous study. MTN and $\mathrm{Ag}^{0}$ nanoparticles had created a synergistic effect which reduced the band gap and functioned as an electron acceptor and plasmonic sensitiser, correspondingly. ${ }^{56}$ Table 1 shows briefly the synthesis means for varied mesoporous $\mathrm{TiO}_{2}$ using cationic surfactant as SDA.

\section{2. Non-Ionic Surfactant}

Non-ionic surfactant is a compound that will not ionise in aqueous solutions even though it possesses hydrophilic parts. During the synthesis of titania nanoparticles, it plays an important role as macro-/mesoporous template. It is normally utilised to construct nanoscale crystal structures under low calcination temperatures and forms macro-/mesoporous structure which contributes in increasing the mass transport capacity, narrowing channels, and constructing more reachable surface area within the materials. ${ }^{57}$

Table 1. Summary of preparation methods using cationic surfactants as SDA.

\begin{tabular}{|c|c|c|c|c|c|c|c|}
\hline Study & Method & Surfactant & Precursor & Cal. Temp. $\left({ }^{\circ} \mathrm{C}\right)$ & Surface area $\left(\mathrm{m}^{2} / \mathrm{g}\right)$ & Pore Size $(\mathrm{nm})$ & Ref. \\
\hline Jaafar et al. & Microwave & CTAB & a TTIP & 600 & $152.0-187.0$ & $1.50-30.00$ & 57 \\
\hline Jaafar et al. & Microwave & CTAB & a TTIP & 600 & $>180.0$ & 11.36 & 58 \\
\hline Casino et al. & Sol-gel & CTAB & ${ }^{b} \mathrm{TiOSO}_{4}$ & 450 & 250.0 & 7.80 & 55 \\
\hline Li et al. & Sol-gel & CTAB & ${ }^{\mathrm{c}} \mathrm{Ti}\left(\mathrm{SO}_{4}\right)_{2}$ & 400 & 84.8 & 8.80 & 56 \\
\hline
\end{tabular}

\footnotetext{
${ }^{a}$ Titanium isopropoxide ${ }^{b}$ Titanium(IV) oxysulphate-sulphuric acid hydrate ${ }^{c}$ Titanium(IV) sulphide
} 
Besides that, this kind of surfactant can promote interaction between hydrogen and metal oxide while aiding in the production of material-surfactant composites. Other than that, higher specific surface area and smaller pore size might be obtained by increasing the template concentrations up to a specific amount. For instance, different amounts of the Pluronic P-123 (P123) give significant changes in mesoporous titania properties. ${ }^{43}$

Pal et al. had synthesised mesoporous $\mathrm{TiO}_{2}$ and $\mathrm{Fe}_{3} \mathrm{O}_{4} @$ mesoporous $\mathrm{TiO}_{2-\mathrm{x}}$ microspheres by combining the surfactant-assisted sol-gel method which used P123 as the template with the inexpensive and eco-friendly spray-drying approach to manufacture gradable mesoporous materials at a large scale. The particle diameter, structure, dispersity, surface area, as well as pore size could be ruled by varying the aspects while pre-hydrolysis and spray-drying reactions took place. In this means of preparation, surfactant was used to form a mesoporous structure. This could be proven by the scanning electron microscope (SEM) results where the as-prepared spheres structure before calcination had shown significantly smooth surfaces in the amorphous state. After calcination and continuing to ultrasonication, amorphous titania was altered into anatase sphere crystals with rougher surfaces and apparent mesopores on the material surfaces. ${ }^{58}$

Smirnova et al. had prepared mesoporous nanosized $\mathrm{TiO}_{2}$ films modified with several transition metal ions via the sol-gel approach with P123 as SDA. The characterisation results showed that manganese doped into $\mathrm{TiO}_{2}$ $\left(\mathrm{m}-\mathrm{TiO}_{2}\right)$ film nanostructures had a mesoporous framework comprised of pore diameters ranging from 2.5 to 6 $\mathrm{nm}$ along with specific surface areas of about 147 and 224 $\mathrm{m}^{2} / \mathrm{g}$ for titania and manganese doped materials, respectively. ${ }^{59}$ Faisal et al. also had synthesised mesoporous titania nanocomposites by the sol-gel technique using Pluronic F127 (F127) as SDA. Simple ultrasonication process was also done to dope $\mathrm{NiO}_{2}$ at different contents into $\mathrm{m}-\mathrm{TiO}_{2}$ nanocomposites for boosting the percentage degradation of methylene blue under visible light illumination. The outcomes showed that $\mathrm{m}-\mathrm{TiO}_{2}$ nanocomposites had surface area and pore diameter of $106.442 \mathrm{~m}^{2} / \mathrm{g}$ and $10 \mathrm{~nm}$, correspondingly, while $\mathrm{NiO} / \mathrm{m}-\mathrm{TiO}_{2}$ nanocomposites showed larger surface area which was $111.3 \mathrm{~m}^{2} / \mathrm{g}$. The $\mathrm{X}$-ray diffraction (XRD) analysis also indicated that $\mathrm{m}-\mathrm{TiO}_{2}$ nanocomposites had an anatase structure while $\mathrm{NiO} / \mathrm{m}-\mathrm{TiO}_{2}$ nanocomposites had a biphasic anatase-rutile structure. $\mathrm{NiO} / \mathrm{m}-\mathrm{TiO}_{2}$ nanoparticles exhibited greatly advanced photoactivity compared to pure mesoporous $\mathrm{TiO}_{2}$ nanoparticles. ${ }^{60}$

Carlo et al. had synthesised mesoporous titania films (TiMS) via the sol-gel approach with P123 as SDA. This template had a major purpose during the production of grains and enhanced their surface roughness. The result revealed that N719 absorbance normalised to titania film thickness $(500 \mathrm{~nm})$ showed TiMS-350 as the most porous sample with the highest dye loading which proved that dye adsorption could be promoted by the coarseness as well as porosity of the material. Thus, the usage of a non-ionic surfactant in TiMS substantially assisted the process while forming compact films with large surface area as well as highly porous. ${ }^{61}$ Moreover, the anatase phase revealed in the TiMS-350 indicated that non-ionic surfactant favoured a low calcination temperature. ${ }^{40}$

Samsudin et al. had utilised F127 as SDA in producing mesoporous titania which had an essential function to boost the photoactivity in atrazine degradation. According to the photoluminescence (PL) spectra and X-ray photoelectron spectroscopy (XPS) analysis, mesoporous F127$\mathrm{TiO}_{2}$ showed a remarkable increment in terms of particle and crystallite size. Higher surface area along with notably reduced size of anatase crystals have generated barely trapping sites where photogenerated electrons or holes were pairing at the molecular level reaction which could facilitate photocatalytic degradation activity. Moreover, the band gap was narrowed to below $3.2 \mathrm{eV}$ (anatase $\left.\mathrm{TiO}_{2}\right) .{ }^{62,63}$ Smirnova et al. also prepared $\mathrm{TiO}_{2}, \mathrm{SiO}_{2}$, and $\mathrm{TiO}_{2}$ doped with $\mathrm{SiO}_{2}\left(\mathrm{TiO}_{2} / \mathrm{SiO}_{2}\right)$ mesoporous films via templated sol-gel synthesis using P123 as SDA for the photodegradation of acridine yellow under UV irradiation. Removal of surfactant had left a mesoporous structure with pore sizes around 2 to $4 \mathrm{~nm}$ on these mesoporous films. Mesoporous $\mathrm{TiO}_{2}$ synthesised via this method also possessed a specific surface area of $910 \mathrm{~m}^{2} / \mathrm{g} .{ }^{64}$

Geramipour and Oveisi had synthesised multilayer nanocrystalline mesoporous $\mathrm{TiO}_{2}$ films via layering deposition combined with surfactant-directed sol-gel approach using P123 as a pore template on glass substrates. Field emission scanning electron microscopy (FESEM) analysis revealed that all materials comprised of integrated pore with sizes less than $20 \mathrm{~nm}$ in nanoparticles were formed from nanocrystallites clusters. The XRD result also exhibited that anatase nanocrystallites were formed with a particle size of $9.60 \mathrm{~nm}$. Low temperature $\left(250^{\circ} \mathrm{C}\right)$ during the pre-heat treatment of the deposited layers produced totally similar multilayer films with no edged coherence present caused by the intense interlinkage along with adequate dissemination layer by layer. ${ }^{65}$

Islam and Rankin had prepared $\mathrm{Ti}^{3+}$ and nitrogen co-doped cubic ordered mesoporous titania thin films using hydrazine technique at different durations and calcination temperatures. During the formation of titania thin films by the sol-gel approach, F127 had been used as SDA. XPS analysis along with UV-Vis absorbance spectra of $\mathrm{Ti}^{3+}-\mathrm{N}-\mathrm{TiO}_{2}$ films illustrated that the incorporation of both elements reduced the band gap of titania and resulted in enhancing the photoactivity upon methylene blue under visible light. The optimum calcination conditions for hydrazine treatment in these films were $350^{\circ} \mathrm{C}$ and $10 \mathrm{~min}$ for high photocatalytic activity. ${ }^{66}$

Islam et al. had prepared cubic ordered mesoporous titania thin films by a surfactant templated sol-gel approach with titanium tetrachloride $\left(\mathrm{TiCl}_{4}\right)$ as the starting 
material and F127 as SDA followed by $\mathrm{N}_{2}$ /Argon plasma treatment for titania doped with nitrogen $\left(\mathrm{N}-\mathrm{TiO}_{2}\right)$. Thermogravimetric analysis (TGA) measurements had been performed to confirm that the calcination step greatly contributed in removing the template and material weight loss was mainly detected at approximately $\sim 300{ }^{\circ} \mathrm{C}$. The SEM result for $\mathrm{TiO}_{2}$ films after calcination showed obvious nanopores at the surface while transmission electron microscopy (TEM) result illustrated the presence of pores throughout the material. The mean pore size and wall thickness of titania films were $7 \mathrm{~nm}$ and $5.5 \mathrm{~nm}$, correspondingly. The specific surface area of the undoped titania film was $143 \mathrm{~m}^{2} / \mathrm{g}$ while for $210 \mathrm{~min}$ of $\mathrm{N}-\mathrm{TiO}_{2}$ films, it was $117 \mathrm{~m}^{2} / \mathrm{g}$. Characterisation analysis showed that the introduction of nitrogen into titania films had lowered the band gap from $3.5 \mathrm{eV}$ to $3.0 \mathrm{eV}$. Therefore, $\mathrm{N}-\mathrm{TiO}_{2}$ films demonstrated better photocatalytic efficiency to degrade methylene blue compared to undoped titania films under visible light. ${ }^{67}$

At first, Dong et al. had synthesised an ordered two-dimensional hexagonal mesoporous anatase crystals-silica nanocomposite by synchronous-assembly of surfactant and inorganic starting material molecules using P123 as the template. The amorphous framework began to crystallise after being calcinated at $350{ }^{\circ} \mathrm{C}$ for the withdrawal of SDA. Phase separation took place and anatase nanoscale crystals were arbitrary inserted into amorphous $\mathrm{TiO}_{2}$ and $\mathrm{SiO}_{2}$ frameworks. Thus, the materials formed had consistent as well as highly silica dispersal structures. After that, three-dimensional interlinkage mesoporous anatase titania were synthesised through silica extraction technique. The characterisation outcomes showed uniform anatase nanocrystals about $13.0 \mathrm{~nm}$ in size and formed a large surface area of around $145 \mathrm{~m}^{2} / \mathrm{g}$. HRTEM image also exhibited that crystals were arbitrarily aligned and linked with the amorphous silica nanoparticles to create "brick-mortar-like" structures. Ink bottle-like struc- tures were produced where almost all crystals were overlapping on the pore partitions, while certain crystals were projected into the mesonecks. The interconnected mesoporous $\mathrm{TiO}_{2}$ also showed better photocatalytic performance for Acid Red and microcystin-LR compared to the parent sample and commercial $\mathrm{TiO}_{2}$ (P25) besides being considerably stable and reusable. ${ }^{68}$

Marco-Brown et al. had synthesised mesoporous titania xerogels via a simple and latent scalable technique according to the EISA method using F127 as a structure directing agent. Varying in synthesis parameters such as relative humidity $(\mathrm{RH})$ and temperature have formed catalysts that demonstrated pores with governable pore and channel size dissemination around 3-12 nm, high specific surface area around $125-161 \mathrm{~m}^{2} / \mathrm{g}$ and pore volume of about 0.17 to $0.38 \mathrm{~cm}^{3} / \mathrm{g}$. Selected area electron diffraction (SAED) and XRD results also demonstrated the existence of anatase phase in the materials produced. Based on the TEM image, granular products exhibited uniform mesopores which resembled bicontinuous worm-like mesophases. All catalysts revealed type IV isotherms which confirmed the mesoporous structure formation. The adsorption kinetics of gallic acid with the textural aspects indicated that larger pore diameter greatly assisted pollutant molecules to enter the particle pores. The catalysts produced also demonstrated a good performance in terms of recoverable and reusable photocatalysts. ${ }^{69}$

Alagarasi et al. had synthesised stable mesostructured titania via the hydrothermal route using P123 surfactant along with different calcination temperatures. The characterisation outcomes indicated that all materials have a wormhole-like porous framework which had spherical particles with the average size of around 6 to $50 \mathrm{~nm}$. Increase in temperature also led to occurrence of phase transition. Among these catalysts, the sample calcined at 550 ${ }^{\circ} \mathrm{C}$ showed the best photoactivity for 4 -chlorophenol due to the co-existence of three crystalline phases of titania

Table 2. Summary of preparation methods using non-ionic surfactants as SDA.

\begin{tabular}{|c|c|c|c|c|c|c|c|}
\hline Study & Method & Surfactant & Precursor & Cal. Temp. $\left({ }^{\circ} \mathrm{C}\right)$ & Surface area $\left(\mathrm{m}^{2} / \mathrm{g}\right)$ & Pore Size (nm) & Ref. \\
\hline Pal et al. & Sol-gel & P123 & a TBOT & 450 & 138.00 & $6.0-7.0$ & 60 \\
\hline Smirnova et al. & Sol-gel & P123 & b TTIP & 400 & 147.00 & $2.5-6.0$ & 61 \\
\hline Faisal et al. & Sol-gel & F127 & a TBOT & 450 & 106.44 & 10.0 & 62 \\
\hline Carlo et al. & Sol-gel & P123 & ${ }^{\mathrm{c}} \mathrm{Ti}\left(\mathrm{OCH}_{3}\right)_{4}$ & 350 & 74.00 & $5.0-35.0$ & 63 \\
\hline Samsudin et al. & Sol-gel & F127 & b TTIP & 500 & 38.77 & - & 64 \\
\hline Smirnova et al. & Sol-gel & P123 & ${ }^{\mathrm{d}} \mathrm{TiC}_{12} \mathrm{H}_{32} \mathrm{O}_{4}$ & 500 & 910.00 & $2.0-4.0$ & 66 \\
\hline Geramipour \& Oveisi & Sol-gel & P123 & b TTIP & 400 & - & $<20.0$ & 67 \\
\hline Islam \& Rankin & Sol-gel & F127 & ${ }^{\mathrm{e}} \mathrm{TiCl}_{4}$ & 350 & 143.00 & 7.0 & 68 \\
\hline Islam et al. & Sol-gel & $\mathrm{F} 127$ & ${ }^{\mathrm{e}} \mathrm{TiCl}_{4}$ & 350 & 143.00 & 7.0 & 69 \\
\hline Dong et al. & $\begin{array}{l}\text { Synchronous } \\
\text { assembly }\end{array}$ & P123 & b TTIP & 350 & 145.00 & 4.7 & 70 \\
\hline Marco-Brown et al. & Sol-gel & $\mathrm{F} 127$ & ${ }^{\mathrm{e}} \mathrm{TiCl}_{4}$ & 350 & $125.00-161.00$ & $3.0-12.0$ & 71 \\
\hline Alagarasi et al. & Hydrothermal & P123 & b TTIP & 350 & 60.00 & 7.9 & 72 \\
\hline Faisal et al. & Sol-gel & F127 & a TBOT & 900 & 85.76 & $10.0-20.0$ & 65 \\
\hline
\end{tabular}

\footnotetext{
a Tetrabutyl titanate ${ }^{\mathrm{b}}$ Titanium isopropoxide ${ }^{\mathrm{c}}$ Titanium(IV) ethoxide ${ }^{\mathrm{d}}$ Tetrapropyl orthotitanate ${ }^{\mathrm{e}}$ Titanium tetrachloride
} 
which enhanced the charge segregation through electron hopping mechanism that facilitated the process. ${ }^{70}$

Faisal et al. had synthesised mesoporous $\mathrm{SrTiO}_{3}$ nanocomposites by the sol-gel method using F127 surfactant. Polythiophene (PTh) doped mesoporous $\mathrm{SrTiO}_{3}$ nanocomposites at varied PTh contents were also prepared by in-situ oxidative polymerisation means. High-resolution transmission electron microscopy (HRTEM) and FESEM images illustrated the shape of undoped $\mathrm{SrTiO}_{3}$ which showed the production of porous and small spherical nanoparticles with sizes $10-20 \mathrm{~nm}$. The FESEM images also revealed that the $\mathrm{PTh}-\mathrm{SrTiO}_{3}$ framework was quite close to the undoped $\mathrm{SrTiO}_{3}$ and possessed type IV isotherm. Undoped $\mathrm{SrTiO}_{3}$ had Brunauer-Emmett-Teller (BET) surface area and total pore volume of $85.76 \mathrm{~m}^{2} / \mathrm{g}^{-1}$ and $0.304 \mathrm{~cm}^{3} / \mathrm{g}$, respectively, while BET surface area values of $0.5,1$, and 10 wt $\% \mathrm{PTh}$ doped $\mathrm{SrTiO}_{3}$ were $118.00 \mathrm{~m}^{2} / \mathrm{g}, 126.66 \mathrm{~m}^{2} / \mathrm{g}$, and $72.36 \mathrm{~m}^{2} / \mathrm{g}$, correspondingly. The rate of photodegradation for $1 \% \mathrm{PTh}-\mathrm{SrTiO}_{3}$ nanocomposite was 4.75 times greater than pure $\mathrm{PTh}$ or undoped $\mathrm{SrTiO}_{3} .{ }^{63}$ Table 2 shows a summary of the preparation methods of mesoporous titania using non-ionic surfactant as SDA.

\section{3. Polymers/Polymeric Fugitive Agent (PFA)}

Polymeric fugitive agents (PFA) can be grouped as surfactants since they aid in the synthesis of mesoporous titania nanoparticles. Heterogeneous, crack-free and intensifying surface roughness of precursor can be obtained by adding the PFA which leads to superior nanostructures production without being coalesced while the calcination takes place. Previously, various types of PFA such as trehalose dihydrate, polyethylene glycol and hydroxypropyl cellulose have been used to structure mesoporous $\mathrm{TiO}_{2}$. The addition of various PFA concentrations during the preparation of titania will affect its porosity. The agglomeration of catalyst surfaces could also be prevented due to the steric repulsion of the PFA and reaction solution mixture which leads to the adsorption onto the surface of titania nanoparticle. Maintaining the titania nanoparticles separated by steric repulsions between PFA layers as well as a sufficient thickness of the coating can be obtained with the addition of a sufficient quantity of PFA into the precursor mixture. The probability for the flocculation and coagulation to occur is low since the segregations by van der Waals attractive forces are too weak. Porous structures of titania catalyst are formed due to the presence of the gaps between the particles in films. ${ }^{71-74}$

Yang et al. had synthesised a three-dimensionally ordered macroporous materials of $\mathrm{CuO} / \mathrm{TiO}_{2}$ via a one-step sol-gel method. Before that, monodisperse polystyrene spheres with diameter about $280 \mathrm{~nm}$ would be synthesised via emulsifier-free emulsion polymerisation to form colloidal crystal templates which acted as PFA in the sol-gel approach to form a mesoporous structure. ${ }^{75}$
Zhang et al. had created C-doped hollow titania spheres by a simple and cost effective in-situ method using monodisperse cationic polystyrene spheres as SDA. After precipitation for titania by the template-assisted sol-gel method was completed, the PFA was separated after calcination at $450^{\circ} \mathrm{C}$. The structure modification of titania into the desired material had enhanced the photocatalytic performance by changing into visible light-activated photocatalyst. The results obtained had indicated that as-synthesised hollow anatase showed outstanding photoactivity in degrading Rhodamine B under visible-light compared to P25 and other titania-based catalysts previously studied. ${ }^{76}$

Study by Liu et al. focused on 3D ordered macro/ mesoporous titania inverse opal films which had been synthesised hierarchically using polyethylene glycol (PEG) associated sol-gel means. For the production of macropores, monodispersed PS microspheres were turned into opal frameworks by the self-assembly approach while PEG 2000 mixed with titanium alkoxide starting material was the SDA. SEM and TEM outcomes from this study revealed that the $3 \mathrm{D}$ ordered macroporous frameworks comprised of $\mathrm{TiO}_{2}$ mesoporous structures with hundreds of nanometre spherical air cavities arrayed in an FCC close-packing arrangement. The mesopores' average size was much larger ( 12 to $25 \mathrm{~nm}$ ) compared to the same material published in other reports. This photocatalyst had improved the amount of organic dyes to be adsorbed, thus increasing the photoactivity. The introduction of the mesopores into the macropores built by disintegrating PFA in the films had attributed to the enhancement of the photocatalytic process besides enriching the reachable surface area of the material, improving the mass transport, and decreasing the length of the mesopore passages. Increment of PFA content up to $2.1 \mathrm{wt}$.\% had improved the photocatalytic performance of the samples and started to decline with further increase in the PFA content. Thus, an immoderate amount of PFA led to the ruining of framework along with a great drop in photoactivity. ${ }^{77}$

Shao et al. had created carbon-doped $\mathrm{TiO}_{2}$ single crystal nanorods with cationic polystyrene spheres/titania $\left(\mathrm{CPS} / \mathrm{TiO}_{2}\right)$ as titania and carbon starting materials by a simple in-situ hydrothermal means for degradation of several organic pollutants under visible light. This approach required the usage of CPS as SDA. The titania starting material was successively deposited and the hydrothermal procedure along with the pyrolysis of CPS were under $\mathrm{N}_{2}$ environment at $450{ }^{\circ} \mathrm{C}$ where the SDA would be removed. FESEM analysis clearly showed that $\mathrm{TiO}_{2}$ nanorods with cubic rod-liked framework had been produced after template removal. This material showed notable photoactivity upon $\mathrm{P} 25$, C-doped $\mathrm{TiO}_{2}$, and blue $\mathrm{TiO}_{2-\mathrm{x}}$ polycrystal due to the intense synergy between carbon dopant and the single crystal framework. ${ }^{78}$ Table 3 shows the brief synthesis means of mesoporous $\mathrm{TiO}_{2}$ using PFA as SDA. 
Table 3. Summary of preparation methods using PFA as SDA.

\begin{tabular}{|c|c|c|c|c|c|c|c|}
\hline Study & Method & Surfactant & Precursor & Cal. Temp. $\left({ }^{\circ} \mathrm{C}\right)$ & Surface area $\left(\mathrm{m}^{2} / \mathrm{g}\right)$ & Pore Size $(\mathrm{nm})$ & Ref. \\
\hline Shao et al. & Hydrothermal & ${ }^{\mathrm{a}} \mathrm{CPS}$ & ${ }^{\mathrm{c}} \mathrm{TBOT}$ & 450 & - & - & 80 \\
\hline Yang et al. & Sol-gel & Polystyrene & ${ }^{\mathrm{d}} \mathrm{TiC}_{8} \mathrm{H}_{24} \mathrm{O}_{4}$ & 500 & 74.00 & 5 to 35 & 77 \\
\hline Zhang et al. & Sol-gel & ${ }^{\mathrm{a}} \mathrm{CPS}$ & ${ }^{\mathrm{e}} \mathrm{TiC}_{16} \mathrm{H}_{40} \mathrm{O}_{4}$ & 450 & 50.27 & $\sim 29$ & 78 \\
\hline Liu et al. & Sol-gel & b PEG 2000 & ${ }^{\mathrm{c}} \mathrm{TBOT}$ & 450 & - & 12 to 25 & 79 \\
\hline
\end{tabular}

${ }^{a}$ Cationic polystyrene spheres ${ }^{b}$ Polyethylene glycol $2000{ }^{c}$ Tetrabutyl titanate ${ }^{d}$ Tetraethyl orthotitanate ${ }^{\mathrm{e}}$ Tetrabutyl orthotitanate

\section{Synthesis Methods}

Generally, self-assembly refers to the building blocks of compound linking via noncovalent bonds like hydrogen bond and van der Waals interaction without exterior interference. This process is usually employed to precursor molecule which will be pre-programmed to enhance its orientation and transformed into a desired supra molecule. EISA approach is a primary means for the formation of desired mesophase compound to further synthesise a mesoporous compound. Amphiphilic surfactants or polymers are usually included in the synthesis procedure since they have hydrophobic and hydrophilic proportions. Beyond the $\mathrm{cmc}$ of aqueous solution, surfactants accumulate forming micelle where the hydrophilic parts are exposed to water, thus preserving the hydrophobic parts inside the micelle. Micelles of different structures of mesophase formed are due to self-organisation upon $\mathrm{cmc}^{32}$ Therefore, many approaches for the conglomerate of mesoporous titania nanoparticle using a similar concept have been developed to improve the synthesis procedure and the expected outcome.

\section{1. Sol-Gel}

The first is sol-gel which is normally used to synthesise ceramic materials at nano-scale by mixing either organic or inorganic precursor and solvents to produce sol which will then form gels. After that, all solvents will be extracted from the gel via drying or the heating process. As for the precursors, they may contain condensed oxide particles or polymeric substances and have metal adjoined by diverse ligands. For instance, methyl alkoxide is one of the frequent precursors used which possesses a metal atom with an organic ligand bound to it. This metaloorganic compound undergoes hydrolysis reaction by reacting with water since hydroxyde ions are present. Afterwards, polycondensation reaction takes place by removing alcohol as well as water molecules from gel and forming xerogel. The process will be continued by heating the xerogel at a certain temperature to form concentrated materials with a better morphology than the original precursor. ${ }^{9,79-81}$ Mesoporous materials can be obtained by controlling various parameters such as temperature in the deposition room, withdrawal rate, and relative humidity. Therefore, it is possible to synthesise varying levels of porosity with an ordered structure, commonly mesoporous transition metal oxides via this approach. ${ }^{82-87}$
Previous studies revealed that the sol-gel method can be further modified into sol-gel/co-hydrolysis which resulted in many varieties of morphology with large surface area, specific pore size, and structures suitable for specific applications by controlling the parameters such as dopant concentration. Initially, sol-gel method is time consuming and usually takes about several days to complete. Sol-gel method also has other disadvantages since it involves many chemicals where the precursor needs to be dissolved in chosen solvents and organic reagents with addition of surfactants or SDA that will be removed using heating and calcination processes, plus it needs to be stirred continuously under certain temperature for a long duration which sometimes takes days to complete the experiment. ${ }^{89,90}$ Thus, the sol-gel technique needs to go through various modifications including being paired with other synthesis methods and adjusting the solvents ratio to surpass these drawbacks for producing various types of $\mathrm{TiO}_{2}$ nanostructures. ${ }^{89-91}$

Olsen et al. had synthesised several mesoporous titania doped with $\mathrm{Al}, \mathrm{La}, \mathrm{Si}$, and $\mathrm{Zr}$ at different molar ratios and calcination temperatures using a modified co-hydrolysis method using solvent deficient approach to compare them in terms of their stability and morphology of the materials. Additionally, this modified method provided a fast and facile way to link stabilisers and titanium precursor under a solvent deficient system by not using any SDA. Most of the drawbacks previously mentioned have been overcome through this method since it involved a fast mixing, easy dissolution in a small amount of water which can be recycled and requires a simple apparatus. This method has a high potential to be scaled up to meet industry requirements. This method produced materials with atypical and desirable characteristics, such as high thermal stability, higher surface area, and better pore diameter distributions compared to previous works. ${ }^{92}$

\section{2. Microwave Assisted}

Nowadays, microwave oven has become one of the essential utensils and it is easy to find in most kitchens because this modern appliance is cost-effective and requires less energy compared to customary meal preparation means. Currently, the employment of microwaves in material synthesis is considered as an advanced establishment rather than only for preparing meals. ${ }^{93}$ Based on the electromagnetic spectrum, microwave radiation has a wave- 
length from $1 \mathrm{~mm}$ to $1 \mathrm{~m}$ with frequency between 0.3 and $300 \mathrm{GHz}$. Regarding the microwaves for varying purposes, two frequencies which are 0.915 and $2.45 \mathrm{GHz}$ commonly have been set aside by the Federal Devices Fee for microwave heat. Since the processing of new material using microwaves has been discovered, the microwave furnaces with larger range of frequency up to $18 \mathrm{GHz}$ were invented in order to make it a more multipurpose appliance. ${ }^{94}$ Miscellaneous techniques were investigated to coalesce the mesoporous titania nanoparticles such as hydrogenation under intense temperature, EISA, plasma treatment, and more. ${ }^{95-98}$ Nevertheless, these procedures are harmful to the environment with inconsistent heat dissemination and require a lot of time for the synthesis to complete. However, the speedy and productive reaction proven by the microwaves makes it preferable for the synthesis of porous materials. ${ }^{99-101}$

Particularly, electrical energy will be converted into microwave energy within the reactor and then applied straight onto the substances where the microwave radiation will heat the reactants but not the reaction container itself. In addition, the heating process involves conversion of electromagnetic to thermal energy. Heat can be supplied throughout the sample since microwaves are capable of penetrating the materials and storing energy. This method affects the nucleation without having a direct contact between the reacting chemicals and energy sources which demonstrates that the volumetric heating does not involve the heat diffusion or the wall. ${ }^{102}$

In fact, energy transfer has high possibility to keep constant and heat the condensed substances quickly without being affected by the heat distribution on the surfaces. Therefore, the heating can be uniform throughout the material which usually leads to less formation of byproducts and/or decomposition products, if the machine is well-designed. The microwave energy is capable to increase the heating rate, reduce the kinetics of crystallisation and potentially form new metastable phases. ${ }^{103}$ Furthermore, this technique offers a steady and speedy process condition as well as yields better materials surface morphology. ${ }^{104}$

In terms of pressure effect within the reactor, the rise in solvent temperature compared to its respective boiling point is expected. In addition, there are various applications of microwave energy especially for mineral and metal recovery processes like leaching, grinding, spent carbon regeneration, and waste management. ${ }^{93,94,105,106}$ Nevertheless, the popularity of using microwave-assisted hydrothermal means in preparing nano-scale materials keeps increasing since it offers a speedy process, volumetric heating capacity, heat selectively, good energy transfer, obtains high purity materials, and good heat distribution throughout the reactants. ${ }^{105}$

Jaafar et al. had prepared mesoporous titania nanoparticles using the microwave approach under varied microwave power densities for photodegradation of 2-chlorophenol. From the result obtained, it was explained that at high power density, heating dispersion consistency has been enhanced with adequate aging to improve the formation between titanium and oxygen bonds and resulted in smaller particle sizes and smoother pore structure. The generation of site defects showed a significant improvement due to condensation while being heated in the microwave which contributes to a separate oxygen surface to produce $\mathrm{OV}$ besides reducing the $\mathrm{Ti}^{4+}$ to $\mathrm{Ti}^{3+}$ sites Compared to commercial $\mathrm{TiO}_{2}$, all the prepared catalysts showed smaller band gap and better photocatalytic activity under visible light rather than UV light. Besides that, these site defects function as an electron acceptor which retard the electron-hole from recombining and also aid in migrating the charge carrier. Kinetic studies revealed that adsorption as the dominating process in degradation of the pollutant obeyed a pseudo-first-order Langmuir-Hinshelwood model. In terms of reusability performance, photodegradation process was maintained, even though the fifth cycle ran with only a slight photocatalyst deactivation. Thus, this investigation successfully demonstrated the consistency of heat dispersal in the microwave which contributed in producing mesoporous titania nanoparticles with generous site defects besides being effective when exposed to visible light. ${ }^{18}$

\section{3. Hydrothermal}

Hydrothermal or also known as solvothermal is a renowned approach since it can directly synthesise a highly controlled shapes for relatively small crystalline structures up to the micro size. ${ }^{107}$ Generally, the synthesis is carried out using autoclave vessel made of steel at high temperature conditions but the crystals agglomerate after reaching the vapour pressure saturation. Therefore, addition of some enhancers, namely stabilising agents is needed to inhibit accumulation. ${ }^{108,109}$ Other than that, this technique is mainly applied for heterogeneous process that employs high temperature or pressure with the solvents present or mineralisers in order to dissolve and recrystallise materials. ${ }^{1,110,111}$

Shao et al. had synthesised carbon-doped $\mathrm{TiO}_{2}$ single crystal nanorods $\left(\mathrm{C}-\mathrm{TiO}_{2}\right)$ using the hydrothermal method. The $\mathrm{C}-\mathrm{TiO}_{2}$ nanorods showed higher degradation compared to $\mathrm{P} 25, \mathrm{C}$-doped $\mathrm{TiO}_{2}$, as well as blue $\mathrm{TiO}_{2-\mathrm{x}}$ polycrystal due to the synergistic effect between carbon dopant and crystal structure. Previously, it was challenging to assimilate dopant into the $\mathrm{TiO}_{2}$ crystal lattice because of its high crystallinity. Therefore, a facile hydrothermal approach had been conducted with $\mathrm{CPS} / \mathrm{TiO}_{2}$ as the starting material for titania nanorods and carbon source to enhance the reaction possibility of $\mathrm{TiO}_{2}$ and $\mathrm{C}$, as well as to increase the possibility of $\mathrm{C}-\mathrm{TiO}_{2}$ single crystal formation. Based on the SEM analysis, the $\mathrm{C}-\mathrm{TiO}_{2}$ single crystal formation via this method had been successfully demonstrated by raising the hydrothermal temperature up to $180^{\circ} \mathrm{C}$. The single crystal nanorods were further confirmed after 
being calcined at $450{ }^{\circ} \mathrm{C}$. Besides, energy-dispersive X-ray (EDX) studies which were carried out to verify the elements present in the samples revealed that the specific element signals were distributed throughout the materials. ${ }^{78}$

\section{4. Sonochemical}

Sonochemical or sonochemistry is an approach which requires the usage of strong ultrasound around $20 \mathrm{kHz}$ up to $10 \mathrm{MHz}$ during the synthesis procedure and resulting in an acoustic cavitation for the creation, expansion, and collapse of bubbles in the mixture. The implode of a bubble creates a constrained hot spot with conditions of around $4730{ }^{\circ} \mathrm{C}$ at 1800 atm with a cooling rate of more than $-164.15{ }^{\circ} \mathrm{C} / \mathrm{s}$ which may be applied to form a well-structured nanomaterial. The effectiveness of this technique can be affected by some factors such as volatile starting materials where it is supposed to be used at the initial reaction site with the vapour contained in the cavitation bubbles.

Previously, Suslick et al. were among the early researchers who managed to synthesise the nanophase of crystalline titania via this method and the modification of this research is still ongoing. ${ }^{112}$ In addition, nanoparticles with a better dispersion, larger surface area, good thermal stability, as well as higher phase purity can be obtained via this method. Other than that, the synthesis approach via sonochemical can help in controlling the mineral growth, influencing the distribution of mineral size, controlling the intended morphology, elimination of impurities in the mineral, removing the need to add seed minerals, and improving the separation performance in solid-liquid. Therefore, this approach appears to be one of the efficient means, especially in synthesising the mesoporous compounds since it is not only generating nucleation (sononucleation) which can affect the crystallisation process but also has a good reproducible capability. ${ }^{113-115}$

Swapna et al. had synthesised mesoporous anatase $\mathrm{TiO}_{2}$ nanopowder via the simple, faster, and inexpensive sol-gel method by ultrasonic irradiation. The application of high intensity ultrasound provided simpler and flexible artificial equipment for nanosized catalysts which cannot be obtained by regular approaches. Several benefits of using ultrasonic irradiation compared to typical methods are improved phase purity, uniform size distribution, and rapid technique. Based on the XRD result, it showed that the mean particle size was around $19 \mathrm{~nm}$ with high purity of anatase titania. ${ }^{116}$

Even though mesoporous titania material possesses diverse prospective implementations for its electronic and optical properties, its framework and surface are hard to modify due to its refractory and quick sol-gel reaction. Therefore, Pal et al. had prepared mesoporous titania microspheres by incorporating the sol-gel method along with the spray-drying approach to overcome this limitation by hierarchically fabricating the intended materials at a large scale. Other than that, elements like metal complex or nanoparticles can be doped in the mesoporous $\mathrm{TiO}_{2}$ microspheres using this method. $\mathrm{Fe}_{3} \mathrm{O}_{4} @$ mesoporous $\mathrm{TiO}_{2-} \mathrm{x}$ microsphere had also been prepared and showed remarkable selective phosphopeptide-enrichment activity. This coupled method was more favourable due to its simple equipment requirement, fast reaction process, low waste, and abundant products compared to the multistep conventional methods. The diameter of bead, pore size, morphology, monodispersity, and surface area could be tuned by differing the parameters during pre-hydrolysis. Alteration of parameters during spray-drying treatment such as compositions, solvents, aging time, temperature and pressure could also enhance their efficiency. The microspheres synthesised had a range of size from $500 \mathrm{~nm}$ to $5 \mu \mathrm{m}$ with surface area between 150 and $162 \mathrm{~m}^{2} / \mathrm{g}$ and average pore size of 4 to $6 \mathrm{~nm} .^{58}$

\section{Role of Dopants}

Surface functionalisation describes the action for surface modification of a material to alter its original properties and characteristic. There are many studies related to surface modification procedures conducted especially for photocatalysts surfaces and addition of dopants which mainly focused on enhancing their optical activity as the main purpose in the modification of titania nanomaterials which can be achieved by altering the activation region from UV to visible. Generally, metals and non-metals usually used as dopants for $\mathrm{TiO}_{2}$ include non-metallic species, transition metals, rare earth elements, plasmonic photocatalysts, alkali and alkaline earth metals, as well as co-doping of metal and non-metal elements. ${ }^{117,118}$ The addition of dopants or coupling with potential elements and compounds will alter the charge-transfer properties between $\mathrm{TiO}_{2}$ and the overall system where the dopant metal will act as trapper to trap the photogenerated electron besides allowing the interfacial charge-transfer processes to improve their catalytic performance. ${ }^{117}$

\section{1. Metal Dopant}

Metal oxide displays distinctive chemical and physical properties due to its composition and multi-structure including specific properties like selective oxidation and electron or ionic separation. These materials also possess the capability to construct different porous mesostructures to be applied for catalysis and energy storage. ${ }^{80}$ As an example, during the synthesis of mesoporous titania, transition metals acting as dopants will be added for improving the photodegradation efficiency. Some of the recent examples for metals and metal oxides commonly used to be doped with titania nanoparticles are $\mathrm{CuO}, \mathrm{Fe}_{2} \mathrm{O}_{3}, \mathrm{SnO}, \mathrm{Zn}$, $\mathrm{Ag}, \mathrm{Cu}$, and $\mathrm{Nb}$, as well as common ions such as $\mathrm{Co}^{2+}$, $\mathrm{Ni}^{2+}, \mathrm{Mn}^{3+}$, and $\mathrm{Cu}^{2+} \cdot{ }^{219-125}$

Generally, transition metal oxides have electrons in the d-orbital compact to nanosized walls, active sites and 
bound pore latticeworks. ${ }^{126}$ Therefore, the segregation capacity for generation of electrons and holes may be increased due to the creation of heterojunctions and electron moving between conduction bands through the incorporation with other transition metal oxide. The photodegradation will be extended by the electron transfer which will inhibit the electron-hole from recombining. Anatase $\mathrm{TiO}_{2}$ mostly can absorb UV light that contains energy source in the form of photons since it possesses a large band gap $(3.20 \mathrm{eV})$. However, solar energy only contains about $5 \%$ of UV photons while domestic lamps mainly comprise of visible photons. A high recombination rate of electron and hole at the photocatalyst surface also contributes in lowering the photodegradation performance. Hence, the usage of accessible solar energy needs to be maximised since the advanced properties of mesoporous $\mathrm{TiO}_{2}$ is to produce and segregate hole and electron. ${ }^{57}$

Luna et. al. had revealed that $\mathrm{CuO}-\mathrm{TiO}_{2}$ composite could be produced via common impregnation method to degrade gallic acid under visible light. The incorporation of $\mathrm{CuO}$ and $\mathrm{TiO}_{2}$ in the range of $0-70 \%$ revealed that $40 \%$ $\mathrm{CuO}$ content showed the best performance for degradation of gallic acid under visible light. After the $\mathrm{CuO}$ loading, the band gap exhibited a remarkable reduction around $1.04 \mathrm{eV}$ from its original value for titania therefore the photocatalyst could be activated under visible light which might be related to a series injection of charge-carriers. As the band gap has shifted to different electromagnetic radiation, the photodegradation performance under UV light after addition of $\mathrm{CuO}$ could no longer show enhancement and only present as impurities or defects on the surface. The production of intermediates like maleic acid after gallic acid degradation took place before reaching mineralisation. ${ }^{127-130}$

Cheng et al. had synthesised $\mathrm{TiO}_{2} / \mathrm{Fe}_{2} \mathrm{O}_{3}$ through calcination of P25 nanoparticles mix with $\mathrm{Fe}_{3} \mathrm{O}_{4}$. The result obtained showed that $\mathrm{TiO}_{2} / \mathrm{Fe}_{2} \mathrm{O}_{3}$ could enhance visible-light activity compared to bare $\mathrm{P} 25$ and $\mathrm{Fe}_{2} \mathrm{O}_{3}$ because of the synergistic effect. Moreover, the result revealed that the coalescence of these two transition metal oxides had promoted movement and segregation of charge carriers which improved photodegradation performance. ${ }^{131}$

\section{2. Non-Metal Dopant}

Non-metal dopants occur as separated atoms at the catalyst surface without clustering, unlike transition metals and have the potential to degrade organic pollutants under UV light. Besides, substantial synergistic properties can also be reached by doping with more than one heteroatom. They fundamentally change the surface transfer of charge carriers by providing limited states in the band gap as well as yielding varied surface morphologies. Carbon nanotubes like graphene and fullerene along with nitrogen are some of the examples for non-metal elements with high potential to introduce into $\mathrm{TiO}_{2} \cdot{ }^{132-136}$ Basically, car- bon usually links with other carbon either by $s p^{3}$ or $s p^{2}$ covalent bonds which lead to differences in molecular morphologies such as nanotubes. Porous carbons possess properties such as chemical inertness, large surface area, high pore volume, mechanical stability, and low cost to make them suitable as adsorbents, catalyst supports, separation membranes, and more. ${ }^{137-140}$

$\mathrm{Li}$ et al. had prepared mesoporous $\mathrm{TiO}_{2} / \mathrm{C}$ composite beads through anion-exchange with resin as carbon source which was then used as an adsorbent-photocatalyst to degrade methyl orange under visible light. These composites demonstrated synergistic effect between carbon and titania due to substantial pore size and surface area. Thus, these composites demonstrated better photocatalytic performance compared to $\mathrm{TiO}_{2}$ alone besides having better absorbance, as well as photocatalytic degradation that could be activated under visible light. In addition, this photocatalyst was easily removed from pollutant due to their bead-like structure which is suitable to be applied for industrial treatment of organic contaminants. ${ }^{141-143}$

Faisal et al. had synthesised mesoporous $\mathrm{NiO} / \mathrm{TiO}_{2}$ composites using varying $\mathrm{NiO}$ percentages via a modified sol-gel technique assisted with triblock copolymer, proceeded by a facile ultrasonic approach for better degradation of methylene blue and gemifloxacin mesylate under visible light. The result of XRD analysis illustrated that a biphasic anatase-rutile structure of this catalyst at different $\mathrm{NiO}$ percentages was found. The production of extremely small titania nanoparticles and $\mathrm{NiO}$ sheet-like framework with particle sizes $10-15 \mathrm{~nm}$ and $30-50 \mathrm{~nm}$ was sequentially confirmed by the TEM results. Besides, this catalyst had a surface area of $111.3 \mathrm{~m}^{2} / \mathrm{g}$ and pore volume of 0.376 $\mathrm{cm}^{3} / \mathrm{g}$. Comparison between this catalyst and its original $\mathrm{NiO}$ nanoparticles showed that this catalyst successfully had better degradation upon methylene blue under visible light irradiation resulting from effective charge segregation while the loading of $0.5 \mathrm{wt} \% \mathrm{NiO}$ into this catalyst exhibited high decomposition upon gemifloxacin mesylate by completing the process after $3 h^{60}$

\section{Conclusion}

Recent advances in science and technology infrastructure especially for semiconductors and nanostructured materials show a remarkable potential to be explored and applied in various applications mainly for the energy, science, and environmental sectors. $\mathrm{TiO}_{2}$ is one of the transition metal oxides which has been studied widely because it has outstanding electrochemical aspects, is inexpensive, chemically and thermally stable, risk-free, inhibits photo-induced reaction, as well as being widely utilised for varied commercial purposes. Therefore, it is necessary for researchers to keep upgrading the $\mathrm{TiO}_{2}$ source by modifying the synthesis approaches, adding potential dopants, 
and inventing new structures. In this review, we have discussed in detail the information regarding the latest research about modification of titania using different surfactants, synthesis methods, the role of dopants and their effect on titania morphology in terms of crystallinity, porosity, and photocatalytic performance. Thus, these basic information, initial inferences, and expectations are provided for further study.

\section{Acknowledgement}

The authors are thankful for the financial support by Ministry of Education Malaysia for Fundamental Research Grant Scheme (203.PKIMIA.6711607) and Universiti Sains Malaysia (USM) for Short Term Grant (304/ PKIMIA/6315055).

\section{List of abbreviations}

\begin{tabular}{|c|c|}
\hline PTh & Polythiophene \\
\hline $\mathrm{BC}$ & Benzalkonium chloride \\
\hline $\mathrm{C}-\mathrm{TiO}_{2}$ & Carbon-doped $\mathrm{TiO}_{2}$ single crystal nanorods \\
\hline $\mathrm{CPS} / \mathrm{TiO}_{2}$ & Cationic polystyrene spheres/titania \\
\hline CTAB & Cetyl-trimethylammonium bromide \\
\hline CTAC & Cetyl-trimethylammonium chloride \\
\hline $\mathrm{P} 25$ & Commercial $\mathrm{TiO}_{2}$ \\
\hline $\mathrm{cmc}$ & Critical micelle concentration \\
\hline Ag-MTN & Silver doped into MTN \\
\hline EDX & Energy-dispersive X-ray \\
\hline EISA & Evaporation-induced self-assembly \\
\hline FESEM & Field emission scanning electron microscopy \\
\hline HRTEM & $\begin{array}{l}\text { High-resolution transmission electron } \\
\text { microscopy }\end{array}$ \\
\hline $\mathrm{m}-\mathrm{TiO}_{2}$ & Manganese doped into $\mathrm{TiO}_{2}$ \\
\hline TiMS & Mesoporous titania films \\
\hline MTN & Mesoporous titania nanoparticles \\
\hline DTAB & n-Dodecyl-trimethylammonium bromide \\
\hline $\mathrm{C}_{18} \mathrm{TAB}$ & Octadecyl-trimethyl ammonium bromide \\
\hline $\mathrm{OV}$ & Oxygen vacancies \\
\hline $\mathrm{PL}$ & Photoluminescence \\
\hline F127 & Pluronic F127 \\
\hline P123 & Pluronic P123 \\
\hline PEG & Polyethylene glycol \\
\hline PFA & Polymeric fugitive agents \\
\hline PTh & Polythiophene \\
\hline SEM & Scanning electron microscope \\
\hline SAED & Selected area electron diffraction \\
\hline SDS & Sodium dodecyl sulphate \\
\hline SDA & Surface directing agent \\
\hline TGA & Thermogravimetric analysis \\
\hline TSD & $\mathrm{Ti}^{3+}$ site defects \\
\hline TEM & Transmission electron microscopy \\
\hline UV & Ultraviolet \\
\hline \multicolumn{2}{|c|}{ UV-Vis DRS UV-Vis Diffuse Reflectance Spectroscopy } \\
\hline XRD & $\mathrm{X}$-ray diffraction \\
\hline XPS & X-ray photoelectron spectroscopy \\
\hline
\end{tabular}

\section{References}

1. D. Dambournet, I. Belharouak, K. Amine, J. Chem. Mater. 2010, 22, 1173-1179. DOI:10.1021/cm902613h

2. F. Amano, R. Tosaki, K. Sato, Y. Higuchi, J. Solid State Chem. 2018, 258, 79-85. DOI:10.1016/j.jssc.2017.09.030

3. A. Abbasi, J. J. Sardroodi, Acta Chim. Slov. 2016, 63, 713-720. DOI:10.17344/acsi.2016.2350

4. Z. Zhang, G. Li, Z. Cui, K. Zhang, Y. Feng, S. Meng, J. Solid State Chem. 2016, 237, 242-247. DOI:10.1016/j.jssc.2016.02.005

5. X. Qu, M. Liu, J. Yang, C. Wang, H. Meng, S. Li, L. Shi, F. Du, J. Solid State Chem. 2018, 264, 77-85.

DOI:10.1016/j.jssc.2018.05.002

6. N. Veronovski, M. Lesnik, A. Lubej, D. Verhovsek, Acta Chim. Slov. 2014, 61, 595-600.

7. A. R. Khataee, M. B. Kasiri, J. Mol. Catal. A Chem. 2010, 328, 8-26. DOI:10.1016/j.molcata.2010.05.023

8. D. Chen, L. Cao, F. Huang, P. Imperia, Y. B. Cheng, R. A. Caruso, J. Am. Chem. Soc. 2010, 132, 4438-4444. DOI:10.1021/ja100040p

9. D. Ramimoghadam, S. Bagheri, S. B. A. Hamid, BioMed Res. Int. 2014, 2014. DOI:10.1155/2014/205636

10. S. D. Mo, W. Y. Ching, J. Phys. Rev. B 1995, 51, 13023-13032. DOI:10.1103/PhysRevB.51.13023

11. O. Sacco, V. Vaiano, C. Daniel, W. Navarra, V. Venditto, Mater. Sci. Semicond. Process. 2018, 80, 104-110. DOI:10.1016/j.mssp.2018.02.032

12. T. Okuno, G. Kawamura, H. Muto, A. Matsuda, J. Solid State Chem. 2016, 235, 132-138. DOI:10.1016/j.jssc.2015.12.025

13. T. W. Kim, M. Park, H. Y. Kim, S. J. Park, J. Solid State Chem. 2016, 239, 91-98. DOI:10.1016/j.jssc.2016.04.010

14. X. D. Zhu, Y. L. Zheng, Y. J. Feng, K. N. Sun, J. Solid State Chem. 2018, 258, 691-694. DOI:10.1016/j.jssc.2017.12.001

15. B. Zhao, Y. W. Chen, J. Phys. Chem. Solids, 2011, 72, 1312 1318. DOI:10.1016/j.jpcs.2011.07.025

16. Y. Liu, G. Ji, M. A. Dastageer, L. Zhu, J. Wang, B. Zhang, X. Chang, M. A. Gondal, RSC Adv. 2014, 4, 56961-56969. DOI:10.1039/C4RA10670A

17. X. Qu, D. Xie, L. Gao, L. Cao, F. Du, J. Mater. Sci. 2015, 50, 21-27. DOI:10.1007/s10853-014-8441-7

18. N. F. Jaafar, A. A. Jalil, S. Triwahyono, N. Shamsuddin, RSC Adv. 2015, 5, 90991-91000. DOI:10.1039/C5RA15120A

19. I. Nadeem, Hani Shaker, Acta Chim. Slov. 2016, 63, 363-368. DOI:10.17344/acsi.2016.2337

20. H. Y. Gan, L. E. Leow, S. T. Ong, Acta Chim. Slov. 2017, 64, 144-158. DOI:10.17344/acsi.2016.2983

21. W. Gao, M. R. Farahani, M. Imran, Acta Chim. Slov. 2017, 64, 256-260. DOI:10.17344/acsi.2016.2947

22. M. Faisal, H. Bouzid, F. A. Harraz, A. A. Ismail, S. A. Al-Sayari, M. S. Al-Assiri, Surf. Coat. Technol. 2015, 263, 44-53. DOI:10.1016/j.surfcoat.2014.12.063

23. N. Wenbin, W. Dengchao, Z. Zhenzhen, H. Zhongjie, Z. Jianwei, J. Chem. Lett. 2010, 39, 98-99.

DOI: $10.1246 / \mathrm{cl} .2010 .98$

24. J. Zhu, W. Mu, L. Su, X. Li, Y. Guo, S. Zhang, Z. Li, J. Solid State Chem. 2017, 248, 142-149. DOI:10.1016/j.jssc.2017.01.028 
25. X. An, C. Gao, J. Liao, X. Wu, X. Xie, Mater. Sci. Semicond. Process. 2015, 34, 162-169. DOI:10.1016/j.mssp.2015.02.003

26. Y. Hao, X. Shao, B. Li, L. Hu, T. Wang, Mater. Sci. Semicond. Process. 2015, 40, 621-630. DOI:10.1016/j.mssp.2015.07.026

27. D. M. Antonelli, J. Y. Ying, Angew. Chem. Int. Ed. Engl. 1995, 34, 2014-2017. DOI:10.1002/anie.199520141

28. D. M. Antonelli, J. Y. Ying, J. Colloid Interface Sci. 1996, 1, 523-529. DOI:10.1016/S1359-0294(96)80122-1

29. N. Ulagappan, C. N. R. Rao, J. Chem. Commun. 1996, 16851686. DOI:10.1039/cc9960001685

30. M. Froba, O. Muth, A. Reller, J. Solid State Ionics 1997, 101103, 249-253. DOI:10.1016/S0167-2738(97)84038-6

31. T. E. W. Niessen, J. P. M. Niederer, T. Gjervan, W. F. Holderich, J. Microporous Mesoporous Mater. 1998, 21, 67-74.

DOI:10.1016/S1387-1811(97)00049-8

32. C. J. Brinker, MRS Bull. 2004, 29, 631-640. DOI: $10.1557 / \mathrm{mrs} 2004.183$

33. W. Wu, L. Zhang, X. Zhai, C. Liang, Kaifeng Yu, Nanomater. Nanotechnol. 2018, 8, 1-8. DOI:10.1177/1847980418781973

34. S. S. Pathak, I. C. Pius, R. D. Bhanushali, K. T. Pillai, J. V. Dehadraya, S. K. Mukerjee, J. Porous Mater. 2013, 20, 753-761. DOI:10.1007/s10934-012-9650-6

35. A. P. Lagrow, B. Ingham, M. F. Toney, R. D. Tilley, J. Phys. Chem. C 2013, 117, 16709-16718. DOI:10.1021/jp405314g

36. Y. Du, L. Zhou, Z. Guo, X. Du, J. Lei, J. Porous Mater. 2019, 26, 1069-1077. DOI:10.1007/s10934-018-0701-5

37. T. Kos, A. Anlovar, E. Zagar, Z. C. Orel, M. Zigon, Acta Chim. Slov. 2014, 61, 497-505.

38. G. Kume, M. Galloti, G. Nunes, J. Surfact. Deterg. 2008, 11, 1-11. DOI:10.1007/s11743-007-1047-1

39. H. Khajuria, J. Ladol, R. Singh, S. Khajuria, H. N. Sheikh, Acta Chim. Slov. 2015, 62, 849-858. DOI:10.17344/acsi.2015.1558

40. M. M. Mohamaed, W. A. Bayoumy, M. Khairy, M. A. Mousa, J. Microporous Mesoporous Mater. 2006, 97, 66-77.

DOI:10.1016/j.micromeso.2006.07.028

41. K. C. J. Li, W. Wang, Y. Zhang, X. Wang, H. Su, Mater. Sci. Semicond. Process. 2012, 15, 20-26.

DOI:10.1016/j.mssp.2011.05.007

42. D. L. Liao, B. Q. Liao, J. Photochem. Photobiol. A Chem. 2007, 187, 363-369. DOI:10.1016/j.jphotochem.2006.11.003

43. G. Calleja, D. P. Serrano, R. Sanz, P. Pizarro, A. Garcia, Ind. Eng. Chem. Res. 2004, 43, 2485-2492. DOI:10.1021/ie030646a

44. M. M. Mohamaed, W. A. Bayoumy, M. Khairy, M. A. Mousa, J. Micro. Meso. Mater. 2007, 103, 174-183.

DOI:10.1016/j.micromeso.2007.01.052

45. J. S. Beck, J. C. Vartuli, W. J. Roth, M. E. Leonowicz, C. T. Kresge, K. D. Schmitt, C. T. W. Chu, D. H. Olson, E. W. Sheppard, S. B. McCullen, J. B. Higgins, J. L. Schlenker, J. Am. Chem. Soc. 1992, 114, 10834-10843.

DOI:10.1021/ja00053a020

46. J. S. Beck, J. C. Vartuli, G. J. Kennedy, C. T. Kresge, W. J. Roth, S. E. Schramm, Chem. Mater. 1994, 6, 1816-1821.

DOI:10.1021/cm00046a040

47. G. Calleja, D. P. Serrano, R. 1. Sanz, P. Pizarro, A. Garcia, Ind. Eng. Chem. Res. 2004, 43, 2485-2492.

DOI:10.1021/ie030646a
48. A. M. Putz, S. Cecilia, C. Ianasi, Z. Dudas, K. N. Szekely, J. Plocek, P. Sfarloaga, L. Sacarescu, L. Almasy, J. Porous Mater. 2015, 22, 321-331. DOI:10.1007/s10934-014-9899-z

49. S. G. Dixit, A. R. Mahadeshwar, S. K. Haram, Colloids Surf. A: Physicochem. Eng. Aspects 1998, 133, 69-75.

DOI:10.1016/S0927-7757(97)00126-X

50. N. Kallay, M. Pastuovic, E. Matijevic, J. Colloids Interface Sci. 1985, 106, 452-458. DOI:10.1016/S0021-9797(85)80019-9

51. S. K. Mehta, K. K. Bhasin, R. Chauhan, S. Dham, Colliod Surf. A: Physicochem. Eng. Aspects 2005, 255, 153-157.

DOI:10.1016/j.colsurfa.2004.12.038

52. V. K. Aswal, P. S. Goyal, Chem. Phys. Lett. 2003, 368, 59-65. DOI:10.1016/S0009-2614(02)01833-X

53. H. Shibata, T. Ogura, T. Mukai, T. Ohkubo, H. Sakai, M. Abe, J. Am. Chem. Soc. 2005, 127, 16396-16397. DOI:10.1021/ja0552601

54. S. Casino, F. Di Lupo, C. Francia, A. Tuel, S. Bodoardo, C. Gerbaldi, J. Alloys Compd. 2014, 594, 114-121. DOI:10.1016/j.jallcom.2014.01.111

55. X. Li, P. Liu, Y. Mao, M. Xing, J. Zhang, App. Catal. B: Environ. 2015, 164, 352-359. DOI:10.1016/j.apcatb.2014.09.053

56. N. F. Jaafar, A. A. Jalil, S. Triwahyono, App. Surf. Sci. 2017, 392, 1068-1077. DOI:10.1016/j.apsusc.2016.09.112

57. W. Li, Z. Wu, J. Wang, A.A. Elzatahry, D. Zhao, J. Chem. Mater. 2013, 26, 287-298. DOI:10.1021/cm4014859

58. M. Pal, L. Wan, Y. Zhu, Y. Liu, Y. Liu, W. Gao, Y. Li, G. Zheng, A. A. Elzatahry, A. Alghamdi, Y. Deng, D. Zhao, J. Colloid Interface Sci. 2016, 479, 150-159.

DOI:10.1016/j.jcis.2016.06.063

59. N. Smirnova, I. Petrik, V. Vorobets, G. Kolbasov, A. Eremenko, Nanoscale Res. Lett. 2017, 12, 239.

DOI:10.1186/s11671-017-2002-3

60. M. Faisal, F. A. Harraz, A. A. Ismail, A. M. El-Toni, S. A. Al-Sayari, A. Al-Hajry, M. S. Al-Assiri, Ceram. Int. 2018, 44, 7047-7056. DOI:10.1016/j.ceramint.2018.01.140

61. G. Di Carlo, G. Calogero, M. Brucale, D. Caschera, T. De Caro, G. Di Marco, G. M. Ingo, J. Alloys Compd. 2014, 609, 116-124. DOI:10.1016/j.jallcom.2014.04.145

62. E. M. Samsudin, S. B. A. Hamid, J. C. Juan, W. J. Basirun, App. Surf. Sci. 2015, 355, 959-968. DOI:10.1016/j.apsusc.2015.07.178

63. M. Faisal, F. A. Harraz, A. A. Ismail, A. M. El-Toni, S. A. Al-Sayari, A. Al-Hajry, M. S. Al-Assiri, Sep. Purif. Technol. 2018, 190, 33-44. DOI:10.1016/j.seppur.2017.08.037

64. N. P. Smirnova, N. I. Surovtseva, T. V. Fesenko, E. M. Demianenko, A. G. Grebenyuk, A. M. Eremenko, J. Nanostruct. Chem. 2015, 5, 333-346. DOI:10.1007/s40097-015-0165-y

65. T. Geramipour, H. Oveisi, Thin Solid Films 2016, 619, 353358. DOI:10.1016/j.tsf.2016.10.030

66. S. Z. Islam, S. E. Rankin, Mater. Chem. Phys. 2016, 182, $382-$ 393. DOI:10.1016/j.matchemphys.2016.07.046

67. S. Z. Islam, A. Reed, D. Y. Kim, S. E. Rankin, Microporous Mesoporous Mater. 2016, 220, 120-128.

DOI:10.1016/j.micromeso.2015.08.030

68. W. Dong, Y. Yao, L. Li, Y. Sun, W. Hua, G. Zhuang, D. Zhou, S. Yan, W. Song, App. Catal. B: Environ. 2017, 217, 293-302. DOI:10.1016/j.apcatb.2017.05.083 
69. J. L. Marco-Brown, M. A. Blesa, G. J. A. A. Soler-Illia, Colloids Surf. A: Physicochem. Eng. Aspects, 2017, 530, 93-103. DOI:10.1016/j.colsurfa.2017.07.054

70. A. Alagarasi, P. U. Rajalakshmi, K. Shanthi, P. Selvam, Catal. Today 2018, 309, 202-211.

DOI:10.1016/j.cattod.2017.08.001

71. F. Chekin, S. Bagheri, S. B. A. Hamid, J. Sens. Actuators B 2013, 177, 898-903. DOI:10.1016/j.snb.2012.12.002

72. V. Nagpal, R. Davis, S. Desu, J. Mater. Res. 1995, 10, 30683078. DOI:10.1557/JMR.1995.3068

73. S. J. Bu, Z. G. Jin, X. X. Liu, L. R. Yang, Z. J. Cheng, J. Eur. Cer. Soc. 2005, 25, 673-679.

DOI:10.1016/j.jeurceramsoc.2003.12.025

74. T. Miki, K. Nishizawa, K. Suzuki, K. Kato, J. Mater. Lett. 2004, 58, 2751-2753. DOI:10.1016/j.matlet.2004.04.015

75. H. Masai, T. Miyazaki, K. Mibu, Y. Takahashi, T. Fujiwara, J. Eur. Ceram. Soc. 2015, 35, 2139-2144.

DOI:10.1016/j.jeurceramsoc.2015.01.013

76. Y. Zhang, Z. Zhao, J. Chen, L. Cheng, J. Chang, W. Sheng, C. Hu, S. Cao, App. Catal. B: Environ. 2015, 165, 715-722. DOI:10.1016/j.apcatb.2014.10.063

77. W. Liu, A. Wang, J. Tang, S. L. Chen, G. Yuan, K. Zhao, C. Li, X. Liu (2015), Microporous Mesoporous Mater. 2015, 204, 143-148. DOI:10.1016/j.micromeso.2014.11.015

78. J. Shao, W. Sheng, M. Wang, S. Li, J. Chen, Y. Zhang, S. Cao, App. Catal. B: Environ. 2017, 209, 311-319.

DOI:10.1016/j.apcatb.2017.03.008

79. D. Verhovsek, M. Lesnik, N. Veronovski, Z. Samardzija, K. Zagar, Miran Ceh, Acta Chim. Slov. 2014, 61, 468-479.

80. N. C. Korosin, N. Bukovec, P. Bukovec, Acta Chim. Slov. 2015, 62, 304-311. DOI:10.17344/acsi.2014.1102

81. B. L. Shinde, L. A. Dhale, V. S. Suryavanshi, K. S. Lohar, Acta Chim. Slov. 2017, 64, 931-937.

DOI:10.17344/acsi.2017.3619

82. P. Innocenzi, S. Costacurta, T. Kidchob, L. Malfatti, P. Falcaro, G. Soler-Illia, J. Sol Gel Methods Mater. Process 2008, 105-123. DOI:10.1007/978-1-4020-8514-7_7

83. A. Marzec, M. Radecka, W. Maziarz, A. Kusior, Z. Pedzich, J. Eur. Ceram. Soc. 2016, 36, 2981-2989.

DOI:10.1016/j.jeurceramsoc.2015.12.046

84. T. Brezesinski, M. Groenewolt, A. Gibaud, N. Pinna, M. Antonietti, B. M. Smarsly, Adv. Mater. 2006, 18, 2260-2263. DOI:10.1002/adma.200600258

85. P. Innocenzi, L. Malfatti, J. Chem. Soc. Rev. 2013, 42, 41984216. DOI: $10.1039 / \mathrm{c} 3 \mathrm{cs} 35377 \mathrm{j}$

86. L. Mahoney, R. T. Koodali, J. Mater. 2014, 7, 2697-2746. DOI: $10.3390 / \mathrm{ma} 7042697$

87. D. E. Clark, D. C. Folz, J. K. West, Mater. Sci. Eng. A 2000, 287, 153-158. DOI:10.1016/S0921-5093(00)00768-1

88. K. E. Haque, Int. J. Miner. Process 1999, 57, 1-24. DOI:10.1016/S0301-7516(99)00009-5

89. J. G. Cerrillo, A. N. C. Mendoza, P. M. M. Romero, A. H. Granados, H. Hu, Mater. Sci. Semicond. Process. 2017, 72, 106-114. DOI:10.1016/j.mssp.2017.08.027

90. W. Zhang, X. Pei, J. Chen, H. He, Mater. Sci. Semicond. Process. 2015, 38, 24-30. DOI:10.1016/j.mssp.2015.04.007
91. N. Nithya, G. Bhoopathi, G. Magesh, C. D. N. Kumar, Mater. Sci. Semicond. Process. 2018, 83, 70-82.

DOI:10.1016/j.mssp.2018.04.011

92. R. E. Olsen, C. H. Bartholomew, B. Huang, C. Simmons, B.F. Woodfield, Microporous Mesoporous Mater. 2014, 184, 7-14. DOI:10.1016/j.micromeso.2013.09.030

93. E. T. Thostenson, T. W. Chou, J. Compos. Part A 1999, 30, 1055-1071. DOI:10.1016/S1359-835X(99)00020-2

94. P. Lidstrom, J. Tierney, B. Wathey, J. Westman, J. Tetrahedron 2001, 57, 9225-9283.

DOI:10.1016/S0040-4020(01)00906-1

95. S. Hoang, S. P. Berglund, N. T. Hahn, A. J. Bard, C. B. Mullins, J. Amer. Chem. Soc. 2012, 134, 3659-3662.

DOI: $10.1021 / \mathrm{ja} 211369 \mathrm{~s}$

96. Z. K. Zhang, M. L. Bai, D. Z. Guo, S. M. Hou, G. M. Zhang, Chem. Commun. 2011, 47, 8439-8441.

DOI:10.1039/c1cc12669e

97. Z. Yuan, X. W. Xiao, H. Lv, C. Z. Wen, J. Phys. Chem. Solids 2007, 68, 1652-1655. DOI:10.1016/j.jpcs.2007.04.001

98. G. D. Bromiley, A. A. Shiryaev, Phys. Chem. Miner. 2006, 33, 426-434. DOI:10.1007/s00269-006-0087-9

99. L. Moradi, M. A. Sadegh, Acta Chim. Slov. 2017, 64, 506-512. DOI:10.17344/acsi.2017.3417

100. A. Srinivas, M. Sunitha, K. Raju, B. Ravinder, S. Anusha, T. Rajasri, P. Swapna, D. Sushmitha, D. Swaroopa, G. Nikitha, C. G. Rao, Acta Chim. Slov. 2017, 64, 319-331.

DOI:10.17344/acsi.2016.3153

101. L. C. Greiler, H. Haase, B. Mahltig, Acta Chim. Slov. 2018, 65, 865-874. DOI:10.17344/acsi.2018.4513

102. N. H. N. Kamarudin, A. A. Jalil, S. Triwahyono, V. Artika, N. F. M. Salleh, A. H. Karim, N. F. Jaafar, M. R. Sazegar, R. R. Mukti, B. H. Hameed, A. Johari, J. Colloid Interface Sci. 2014, 421, 6-13. DOI:10.1016/j.jcis.2014.01.034

103. S. Komarnenia, R. K. Rajha, H. Katsuki, Mater. Chem. Phys. 1999, 61, 50-54. DOI:10.1016/S0254-0584(99)00113-3

104. M. Shi, L. Kang, Y. Jiang, C. Ma, Catal. Lett. 2014, 144, 278 284. DOI:10.1007/s10562-013-1132-1

105. D. E. Clark, D. C. Folz, J. K. West, J. Mater. Sci. Eng. A 2000, 287, 153-158. DOI:10.1016/S0921-5093(00)00768-1

106. K. E. Haque, Int. J. Min. Process 1999, 57, 1-24. DOI:10.1016/S0301-7516(99)00009-5

107. Z. Bo, R. Dong, C. Jin, Z. Chen, Mater. Sci. Semicond. Process. 2017, 72, 9-14. DOI:10.1016/j.mssp.2017.09.011

108. S. Liu, J. Huang, L. Cao, J. Li, H. Ouyang, X. Tao, C. Liu, Mater. Sci. Semicond. Process. 2014, 25, 106-111.

DOI:10.1016/j.mssp.2013.09.021

109. X. Zhang, D. Li, J. Wan, X. Yu, Mater. Sci. Semicond. Process. 2016, 43, 47-54. DOI:10.1016/j.mssp.2015.11.020

110. R. Singh, M. Kumar, H. Khajuria, J. Ladol, H. N. Sheikh, Acta Chim. Slov. 2018, 65, 319-327. DOI:10.17344/acsi.2017.3988

111. K. Pourzare, S. Farhadi, Y. Mansourpanah, Acta Chim. Slov. 2017, 64, 945-958. DOI:10.17344/acsi.2017.3642

112. K. S. Suslick, T. Hyeon, M. Fang, A. A. Cichowlas, J. Mater. Sci. Eng. A 1995, 204, 186-192.

DOI:10.1016/0921-5093(95)09958-1 
113. A. Gedanken, J. Ultrason. Sonochem. 2004, 11, 47-55. DOI:10.1016/j.ultsonch.2004.01.037

114. T.J. Mason, J. Ultrason. Sonochem. 2007, 14, 476-483. DOI:10.1016/j.ultsonch.2006.10.008

115. T. Froschl, U. Hormann, P. Kubiak, G. Kucerova, M. Pfanzelt, C.K. Weiss, R.J. Behm, N. Husing, U. Kaiser, K. Landfesterd, M. Wohlfahrt-Mehrensc, J. Chem. Soc. Rev. 2012, 41, 5313-5360. DOI:10.1039/c2cs35013k

116. M. V. Swapna, K. R. Haridas, J. Exp. Nanosci. 2016, 11, 540549. DOI:10.1080/17458080.2015.1094189

117. T. Parangi, M. K. Mishra, Comments Inorg. Chem. 2019, 39, 90-126. DOI:10.1080/02603594.2019.1592751

118. L. Guo, C. Zhang, L. Xu, M. Li, Q. Wang, F. Ye, C. Dan, V. Ji, J. Eur. Ceram. Soc. 2017, 37, 4163-4169.

DOI:10.1016/j.jeurceramsoc.2017.04.065

119. W. J. Tseng, P. Lin, J. Eur. Ceram. Soc. 2017, 37, 5265-5272. DOI:10.1016/j.jeurceramsoc.2017.03.040

120. M. Duta, L. Predoana, J. M. Calderon-Moreno S. Preda, M. Anastasescu, A. Marin, I. Dascalu, P. Chesler, C. Hornoiu, M. Zaharescu, P. Osiceanu, M. Gartner, Mater. Sci. Semicond. Process. 2016, 42, 397-404.

DOI:10.1016/j.mssp.2015.11.004

121. Y. Wang, J. Tao, X. Wang, Z. Wang, M. Zhang, G. He, Z. Sun, Ceram. Int. 2017, 43, 4866-4872.

DOI:10.1016/j.ceramint.2016.12.130

122. K. Usha, P. Kumbhakar, B. Mondal, Mater. Sci. Semicond. Process. 2016, 43, 17-24. DOI:10.1016/j.mssp.2015.11.015

123. M. Sreedhar, I. N. Reddy, C. V. Reddy, J. Shim, J. Brijitta, Mater. Sci. Semicond. Process. 2018, 85, 113-121.

DOI:10.1016/j.mssp.2018.06.005

124. H. Masai, T. Miyazaki, K. Mibu, Y. Takahashi, T. Fujiwara, J. Eur. Ceram. Soc. 2015, 35, 2139-2144.

DOI:10.1016/j.jeurceramsoc.2015.01.013

125. W. Subramonian, T. Y. Wu, S. P. Chai, J. Environ. Manage. 2017, 187, 298-310.

DOI:10.1016/j.jenvman.2016.10.024

126. Y. Ren, Z. Ma, P. G. Bruce, J. Chem. Soc. Rev. 2012, 41, 49094927. DOI:10.1039/c2cs35086f

127. A. L. Luna, M. A. Valenzuela, C. Colbeau-Justin, P. Vázquez, J. L. Rodriguez, J. R. Avendaño, S. Alfaro, S. Tirado, A. Gar- duno, J. M. De La Rosa, App. Catal. A: Gen. 2016, 521, 140148. DOI:10.1016/j.apcata.2015.10.044

128. M. Lei, N. Wang, L. Zhu, Q. Zhou, G. Nie, H. Tang, App. Catal. B: Environ. 2016, 82, 414-423.

DOI:10.1016/j.apcatb.2015.09.031

129. B. Li, Y. Hao, B. Zhang, X. Shao, L. Hu, App. Catal. A: Gen. 2017, 531, 1-12. DOI:10.1016/j.apcata.2016.12.002

130. M. Rokhmat, E. Wibowo, Sutisna, Khairurrijal, M. Abdullah, Procedia Eng. 2017, 170, 72-77.

DOI:10.1016/j.proeng.2017.03.014

131. L. Cheng, S. Qiu, J. Chen, J. Shao, S. Cao, Mater. Chem. Phys. 2017, 190, 53-61. DOI:10.1016/j.matchemphys.2017.01.001

132. C. H. Park, C. M. Lee, J. W. Choi, G. C. Park, J. H. Joo, Ceram. Int. 2018, 44, 1641-41645.

DOI:10.1016/j.ceramint.2017.10.086

133. N. Rozman, L. Skrlep, M. Gaberscek, A. S. Skapin, Acta Chim. Slov. 2014, 61, 506-516.

134. U. Prah, I. K. Skofic, Acta Chim. Slov. 2017, 64, 877-887. DOI:10.17344/acsi.2017.3497

135. Y. Li, J. Yan, Q. Su, E. Xie, W. Lan, Mater. Sci. Semicond. Process. 2014, 27, 695-701. DOI:10.1016/j.mssp.2014.08.001

136. K. Yu, C. Zhang, Y. Chang, Y. Feng, Z. Yang, T. Yang, L. Lou, S. Liu, App. Catal. B: Environ. 2017, 200, 514-520.

DOI:10.1016/j.apcatb.2016.07.049

137. N. R. Khalid, A. Majid, M. B. Tahir, N. A. Niaz, S. Khalid, Ceram. Int. 2017, 3, 14552-14571. DOI:10.1016/j.ceramint.2017.08.143

138. W. Li, Z. Wu, J. Wang, A. A. Elzatahry, D. Zhao, J. Chem. Mater. 2014, 26, 287-298. DOI:10.1021/cm4014859

139. Y. Wan, H. Yang, D. Zhao, J. Acc. Chem. Res. 2006, 39, 423432. DOI:10.1021/ar050091a

140. Y. Wan, Y. Shi, D. Zhao, J. Chem. Mater. 2008, 20, 932-945. DOI:10.1021/cm7024125

141. X. Li, Y. Jiang, W. Cheng, Y. Li, X. Xu, K. Lin, Nano-Micro Lett. 2015, 7, 243-254. DOI:10.1007/s40820-015-0029-5

142. C. Andriantsiferana, E. F. Mohamed, H. Delmas, Environ. Technol. (United Kingdom) 2014, 35, 355-363.

DOI:10.1080/09593330.2013.828094

143. V. R. Posa, V. Annavaram, J. R. Koduru, P. Bobbala, V. Madhavi, A. R. Somala, J. Exp. Nanosci. 2016, 11, 722-736. DOI:10.1080/17458080.2016.1144937

\section{Povzetek}

Titanov dioksid $\left(\mathrm{TiO}_{2}\right)$ se široko uporablja kot fotokatalizator zaradi svoje dobre stabilnosti in učinkovitosti pri razkroju onesnaževal. Po drugi strani pa je njegova fotokatalitska učinkovitost omejena, ker se vzbudi le pod UV svetlobo in ker med fotorazkrojem prihaja do hitre rekombinacije med elektroni in prazninami. Mnoge raziskave se osredotočajo na uravnavanje metod sinteze, dodatke dopantov in spreminjanje strukture $\mathrm{TiO}_{2} \mathrm{z}$ namenom povečanja fotokatalitske učinkovitosti. Med temi je sinteza $\mathrm{TiO}_{2} \mathrm{v}$ obliki poroznih nanodelcev ena od strategij modificiranja strukture $\mathrm{TiO}_{2}$, ki je zlasti pritegnila pozornost zaradi svojih prednosti, kot so: boljša adsorpcija in dostopnost različnih onesnaževal do reaktivnih mest na katalizatorju, kar izboljša fotokatalitsko učinkovitost. V tem pregledu literature povzemamo modifikacije sinteznih metod $\mathrm{za} \mathrm{TiO}_{2}$ in njihov učinek na strukturo ter fotokatalitsko učinkovitost. Novejši razvoj na področju $\mathrm{TiO}_{2}$ glede sinteznih pristopov, učinka dopantov, modificiranih struktur and uporabe je ravno tako predstavljen.

Except when otherwise noted, articles in this journal are published under the terms and conditions of the Creative Commons Attribution 4.0 International License 